\title{
Harnessing Emerging Technologies for Education Communication
}

\section{Peter Kibe Ngugi*}

Jkuat University, Juja, Kenya

\begin{abstract}
The history of pedagogy reflects many changes in methodology, curriculum and institutional structure and management but one thing that seems to transcend time is the central role of the classroom teacher. At all levels of learning from the preparatory to higher levels of education, the role of the instructor remains paramount. Even informally, in apprenticeship the trainer plays a significant role in transmission and imparting of knowledge. Educationists have made bold attempts to integrate communication technologies to enrich learning with tremendous success but they all serve to complement the role of the teacher. The education fraternity can be noted without fear of contradiction to be the greatest beneficially of the printing technology. Discoveries of other communication technologies like the motion pictures, the television, radio, computer, internet and digital technologies have all played significant roles in improving transmission of educational instructions.

The new media hold promise of stealing the show from the classroom teacher more than any other communication technology so far discovered. There is need to urgently assess the impact these new media technologies have had on learning and their contribution to quality compared to older technologies and the traditional classroom teacher. However, this is not the focus of this paper. The concern of this paper is to explore the variety of new media technologies available for learning and how they can be used to enrich learning.

Through literature review method this article poignantly demonstrates how the new media is being used to complement the efforts of the classroom instructor through offline and online presentations, publishing online and offline, social networking, access, connectivity, search, analytical tools, content creation and design and providing a rich online resources.
\end{abstract}

"The newly released ICT figures confirm once again that information and communication technologies continue to be the key drivers of the information society," ITU Secretary-General Hamadoun I. Touré.

Keywords: Education communication and technology; New media; Social media; Multimedia; e-learning and ICT

\section{Introduction}

It is a puzzle why education technologies like the radio, television, motion pictures and computer have failed in the last 100 years to replace the teacher aided learning. Cuba [1] claim that a review of education technologies of the twentieth century shows that technology-centered approach generally fails to lead to lasting improvements in education. Norman [2] remarks that much of the science and technology takes a machine centered view of the design so that instead of aiding human cognition it often interferes and confuses.

A simple dictionary meaning of the term technology state that it is the knowledge of the practical and especially industrial, use of scientific discoveries. According to Mcluhan [3], technology refers to human inventions that enhance communication. The new technologies like alphabets, printing press, electronic media and now digital communication have effect on man's cognition and social organization which in turn affect the culture of the society. Today more electronic discoveries have been made like the computer, the TV, the Internet, the Cellular phone, radio etc. Human societies are no longer closed systems but interconnected. The Internet as an extension of our consciousness is an electric technology that enables instantaneous movement of information from every quarter to every point at the same time. Electric speed heightens human awareness. Web connections have created new social realities in communication culture. The electronic media in form of World Wide Web create unified communities.

Among the older communication technologies is the film. The inventor of motion picture Thomas Edison predicted that it would revolutionize the education system and it would supplant almost entirely the use of books. He claimed that it is possible to teach every branch of human knowledge with the motion pictures but this is not the case today.

Cuba [1] observes that a review of the education system shows that teachers use films infrequently in their classrooms. Further, he notes that in 1945 the director of Ohio School of the Air predicted that radio receiver will be as common in the classroom as the black board and radio instructions will be integrated into school life. Today the opposite is true, even here in Kenya, radio as a medium of instruction is rarely used and the KBC Radio Broadcast programmes for schools have collapsed or play insignificant role in education.

The TV has a similar history, in its peak in the 1950s educationist thought that it would provide richer education at less cost but today teachers use TV in class infrequently if at all [1].

Computer is the greatest technological accomplishment of the $20^{\text {th }}$ Century. Computer mediated technologies can integrate audiovisual aids like videos, music and photos. In 1960s tutoring machines were predicted that they would replace teachers. Computer Aided Instruction (CAI) [4] in which computers presented short frames

*Corresponding author: Peter Kibe Ngugi, Jkuat University, Juja, Kenya, Tel: +254 020 28500; E-mail: ngugi.leoking@gmail.com

Received May 04, 2014; Accepted July 22, 2014; Published July 29, 2014

Citation: Ngugi PK (2014) Harnessing Emerging Technologies for Education Communication. J Mass Communicat Journalism 4: 207. doi:10.4172/21657912.1000207

Copyright: (c) 2014 Ngugi PK. This is an open-access article distributed under the terms of the Creative Commons Attribution License, which permits unrestricted use, distribution, and reproduction in any medium, provided the original author and source are credited. 
solicited a response from the learner and provided feedback to the learner in computer projects like PLATO and TICCIT which failed to produce better learning than the traditional teacher led instruction [5]. The so called cutting edge technology has failed to revolutionize education system and has remained a chronicle of technological disappointments leaving educationists with the only option of the traditional classroom teacher.

Incorporating multimedia technology into emerging communication technology such as internet will present an option for presenting information effectively to an online audience sometimes with the advantage of seeing the lecturer on a window of a computer screen hence experiencing the feeling of a live lecture.

Multimedia is integrating both words such as spoken text or printed text and pictures such as illustrations, photos, animation or video. Mayer E. Richard [6] of university of California Santa Barbara defines multimedia as presenting both words in various forms as spoken text or printed text and pictures such as illustrations, photos, animation or video. This may include watching a video on a TV screen and corresponding words, music, sounds or watching a PowerPoint presentation through a projector along with voice. Multimedia technology can be used online or offline.

Shannon Rupp in a paper [4] posits that technology is evolving rapidly and opening doors for a variety of sectors including education. In continental Africa, countries are embracing information and communications technology (ICT) [7] to increase access to the Internet and expand educational curricula at all levels of schooling. $\mathrm{He}$ notes that, a growing body of evidence shows that old ways of learning across the continent are not getting the desired results, so it has been necessary to introduce new ways of approaching education provision thus businesses, schools and communities are now increasingly focusing on ensuring that people are becoming more literate in ICT.

ICTs are technologically mediated communication methods. E-learning, which is the use of ICT in education is, is quickly becoming an asset not only to the students but to communities and teachers as well. It provides the means for gaining stronger work skills, allows for global partnerships to develop, and increases the quality of education programmes. Expanding access to and the availability of e-learning programmes for students, teachers and businesses is a key to furthering continental development and growth.

Shannon adds, technology and its content are changing communication and publications in schools. Interactive textbooks and educational games are being introduced into schools, creating an environment like an online digital classroom. Advances in mobile services have also provided the means to expand community knowledge about the Internet and wireless technology. Overall, the use of ICT has grown exponentially across the continent in the past decade.

Shannon cites new kinds of content that are in development regularly and are being introduced to children and adults. For example, digital textbooks are being introduced, replacing conventional two dimensional publications and books. In South Africa for example, about 1.5 million students can now access computer classrooms through upgraded computer technology.

Shannon concludes that education through e-learning is becoming vital in opening new doors, not only for children but also for adults. It is slowly allowing women to strengthen their positions in society through increased access to information and opportunities and is providing independence and ICT awareness. It is noted that in order to continue this growth the expansion of education through e-learning must occur and that, in the African context, this is only possible through the increased use of ICT and continued training through large scale-up programmes. In this way education in both urban and rural areas will be improved by access to information through technology, learning and the Internet.

The Ministry of education in Rwanda [8] term the "one laptop per child" programme a great success. Through this initiative, school children across the country have not only gained access to information technology, but for many it's their first opportunity to learn how to use a computer; a skill that is essential in today's working world. They train teachers to use these laptops in delivering their lessons. The laptops are loaded with educational material that is consistent with the Rwandan curriculum. However since the memory capacity is limited, they plan to purchase servers for schools which will allow them to store even more materials. We are also working on giving all schools access to high speed internet which will really show the full potential of this programme.

This Ministry observes that they have adopted ICT laboratory models for secondary schools, meaning each school gets one or two computer labs. They use these to teach several courses-not just ICT. As high internet bandwidth becomes increasingly available, these ICT labs will also serve as e-libraries and e-laboratories for various science subjects such as chemistry, physics and biology. Also, with the support of USAID, the Ministry of Education has developed an education portal which allows teachers and students to access and exchange work as well as other educative material.

The internet is set to play a major role in the future of education world over. Robb, perhaps more than any other current form of communication technology, the Internet often receives praise for its facilitation in the construction and maintenance of virtual communities. In addition to providing a means for connecting to Diaspora and communities of interest, the technology of the Internet allows users to create and distribute their own audio, print, and visual media online.

Internet is a world-wide computer network that can be accessed via a computer, mobile telephone, PDA, games machine, digital TV, etc. The Internet access service can be provided through a fixed (wired) or mobile network: analogue dial-up modem via standard telephone line, ISDN (Integrated Services Digital Network), DSL (Digital Subscriber Line) or ADSL, Cable modem, High speed leased lines, Fiber, Powerline, Satellite broadband network, WiMAX, Fixed CDMA, Mobile broadband network (3G, e.g. UMTS) via a handset or card, Integrated SIM card in a computer, or USB modem.

International Telecommunications Union (ITU) [9] indicates that by end 2014, the number of Internet users globally will have reached almost 3 billion. Two-thirds of the world's Internet users are from the developing world. This corresponds to an Internet-user penetration of 40 per cent globally, 78 per cent in developed countries and 32 per cent in developing countries. More than 90 per cent of the people who are not yet using the Internet are from the developing world.

In Africa, almost 20 per cent of the population will be online by end 2014, up from 10 percent in 2010.

In the Americas, close to two out of three people will be using the Internet by end 2014, the second highest penetration rate after Europe. Europe's Internet penetration will reach 75 per cent (or three out of four people) by end 2014, the highest worldwide. One-third of 
the population in Asia and the Pacific will be online by end 2014 and around 45 per cent of the world's Internet users will be from the AsiaPacific region.

Internet live stats study in 2014 show that nearly $75 \%$ (2.1 billion) of all internet users in the world ( 2.8 billion) live in the top 20 countries. The remaining $25 \%$ ( 0.7 billion) is distributed among the other 178 countries, each representing less than $1 \%$ of total users. China, the country with most users (642 million in 2014), represents nearly $22 \%$ of total, and has more users than the next three countries combined (United States, India, and Japan).

Among the top 20 countries, India is the one with the lowest penetration: $19 \%$ and the highest yearly growth rate. At the opposite end of the range, United States, Germany, France, U.K., and Canada have the highest penetration: over $80 \%$ of population in these countries has an internet connection (Table 1).

The Communications Commission of Kenya (CCK) figures in its ICT Sector Quarterly Statistical Report for the fourth quarter of the financial year 2012/2013 indicate that Internet penetration has increased by 61.2 per cent year-on-year in Kenya, boosted primarily by an increase in mobile data subscriptions as well as internet subscriptions. On a quarter-on-quarter basis, internet users increased from 16.4 million to 19.6 million [12], representing a 19.5 per cent increase. Kenya now has a 49.7 per cent penetration rate, up from 41.6 percent. The report foresees an increased internet uptake in the coming period especially with the ongoing ICT for schools project and the increased investment in fibre networks across the country.

Mobile cellular communication will also contribute significantly to the education sector especially in boosting access for people with no computers. ITU 2014 release on Mobile-cellular subscriptions project that it will reach almost 7 billion by end 2014, and 3.6 billion of these will be in the Asia-Pacific region. The increase is mostly due to growth in the developing world where mobile-cellular subscriptions will account for 78 per cent of the world's total.

Africa and Asia and the Pacific, where penetration will reach 69 per cent and 89 per cent, respectively by end 2014 , are the regions with the strongest mobile-cellular growth (and the lowest penetration rates). Penetration rates in the Commonwealth of Independent States (CIS), Arab States, the Americas and Europe have reached levels above 100 per cent and are expected to grow at less than two per cent in 2014.
The region with the highest mobile-cellular penetration rate is the CIS (Figure 1).

\section{New Media: A Metaphor for Emerging Technology}

Basically all mass media channels can fall into any of the following categories: Print media in the form of books, newspapers, magazines, newsletters; Recording media in forms such as music, records, tapes, cartridges, cassettes, discs; Film media in forms like cinema, movies, tapes, cassettes, discs; Radio media in forms like music, information, drama, comedy, wired, wireless; Television media packaged as drama, comedy, music, information, wired, wireless; Internet media accessed through websites, downloading, streaming and Mobile media also accessed through websites, downloading, streaming to cellphones and laptops.

The Internet or World Wide Web and mobile media are also referred to as digital media. The mobile media is set to overtake all other media in usage because it has the following qualities: it is personal, it is always with you, it is always turned on, it is at hand when you have creative inspiration, it captures the social context of media consumption, it allows augmented reality in media, it comes with a built-in payment mechanism, it gives an accurate audience measurement. This media is rapidly changing and is able to transcend geographical location, time and all convenience, so more than anything else it will have major impact on how communication will be done in future.

Lawson [13] states that new Media reuses the conventions of Old Media: TV, film, radio, telephone, and print. Even the computer operating system is an iconography of an office that has files, folders, and trashcans. On websites we find shopping carts, picture albums, radio streams, and telephone services. It is clear that the New Media platform is one that has consumed most Old Media forms. New Media conventions are remixed Old Media conventions. The remixing also spans Old Media content. The remixing of content and conventions is how New Media attempts to generate meaning.

Cambridge Online Business Dictionary [14], refer to new media as products and services that provide information or entertainment using computers or the internet, and not by traditional methods such as television and newspapers.

Lev Manovich's [15] argument is that new media is a combination of multimedium into one form. Mark Tribe's writes in New Media Art [16] that New Media is a mixture of Media Art along with Art and

\begin{tabular}{|c|c|c|c|c|c|c|c|c|c|}
\hline Rank & Country & $\begin{array}{l}\text { Internet } \\
\text { Users }\end{array}$ & 1 Year & 1 Year & $\begin{array}{l}\text { Total Country } \\
\text { Population }\end{array}$ & $\begin{array}{c}1 \text { Year Population } \\
\text { Change }(\%)\end{array}$ & Penetration & $\begin{array}{l}\text { Country's } \\
\text { share of World } \\
\text { Population }\end{array}$ & $\begin{array}{c}\text { Country's share } \\
\text { of World Internet } \\
\text { Users }\end{array}$ \\
\hline & & & Growth \% & User Growth & & & $\begin{array}{l}\text { (\% of Pop. with } \\
\text { Internet) }\end{array}$ & & \\
\hline 1 & China & $6.42 \mathrm{E}+08$ & 0 & 24021070 & $1.39 \mathrm{E}+09$ & 0 & 0 & 0 & 0 \\
\hline 2 & United States & $2.80 E+08$ & 0 & 17754869 & $3.23 E+08$ & 0 & 1 & 0 & 0 \\
\hline 3 & India & $2.43 E+08$ & 0 & 29859598 & $1.27 \mathrm{E}+09$ & 0 & 0 & 0 & 0 \\
\hline 4 & Japan & $1.09 \mathrm{E}+08$ & 0 & 7668535 & $1.27 \mathrm{E}+08$ & 0 & 1 & 0 & 0 \\
\hline 5 & Brazil & $1.08 \mathrm{E}+08$ & 0 & 6884333 & $2.02 E+08$ & 0 & 1 & 0 & 0 \\
\hline 6 & Russia & 84437793 & 0 & 7494536 & $1.42 E+08$ & 0 & 1 & 0 & 0 \\
\hline 7 & Germany & 71727551 & 0 & 1525829 & 82652256 & 0 & 1 & 0 & 0 \\
\hline 8 & Nigeria & 67101452 & 0 & 9365590 & $1.79 \mathrm{E}+08$ & 0 & 0 & 0 & 0 \\
\hline 9 & United Kingdom & 57075826 & 0 & 1574653 & 63489234 & 0 & 1 & 0 & 0 \\
\hline 10 & France & 55429382 & 0 & 1521369 & 64641279 & 0 & 1 & 0 & 0 \\
\hline
\end{tabular}

Source: Internet Live Stats (www.InternetLiveStats.com) [10] Elaboration of data by International Telecommunication Union (ITU) [11], United Nations Population Division, Internet and Mobile Association of India (IAMAI), World Bank. July 12014 Estimate

Table 1: List of Top 10 Countries by Internet Usage (2014). 


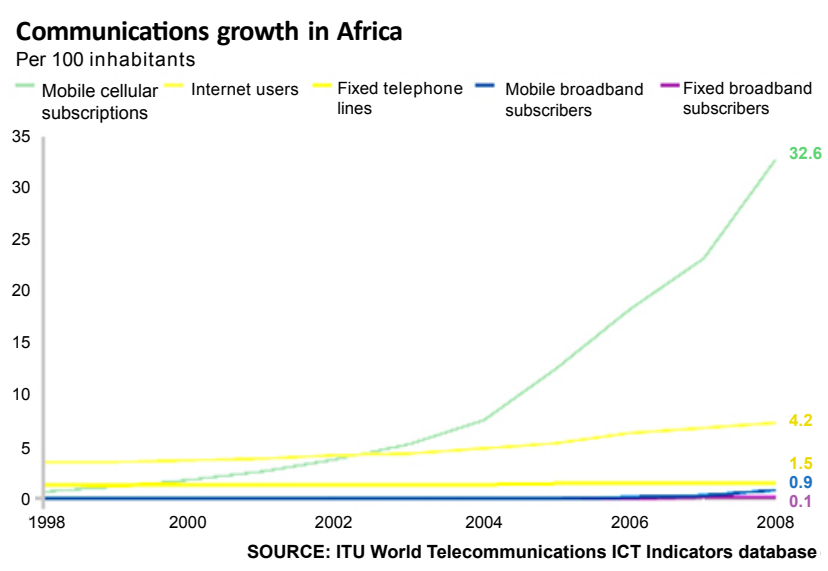

Figure 1: \% of communications growth in Africa [11].

Technology. He defends his position by saying, “...we use the term New Media art to describe projects that make use of emerging media technologies and are concerned with the cultural, political and aesthetic possibilities of these tools."

Social networking platforms are referred to as social media. According to Cambridge Online Business Dictionary, social media refer to websites and computer programs that allow people to communicate and share information on the internet using a computer or mobile phone:

Networking in New Media has two major components. The first is the ability for consumer level mass communication. The second is that the Internet is a mass database of collective consciousness. The ability to send or receive media has been greatly facilitated with the Internet. We are able to be tele-present at meetings, conferences, or with family. Web cameras allow us to have 'distance seeing' powers.

NMC Horizon Report [16], the Internet is a place of public and private information. Social networking is about making connections and bringing people together. Conversations that take place in social networking contexts are inherently social, and often revolve around shared activities and interests. The heart of social networking is fostering the kinds of deep connections that occur when common pursuits are shared and discussed.

Kenyatta university virtual learning Centre in the institution's Post Modern Library is a good example of how new media can be utilized to aid teaching and learning through utilization of online resources. A few secondary schools in Kenya have computer laboratories where students are provided with desk top computers with access to the internet through Wi Fi or Local Area Networks to aid research. Online and Offline materials are provided in form of videos for literature set books, Encyclopaedia, Wikis and other search engines, Encarta etc. Particular rural schools with such resources include Bongo Girls in Kinangop and Ndutumi in Makuyu.

Research by and Tweet minster in 2011 found Kenya as Africa's second most active country on Twitter after South Africa. Marvin Tumbo in a blog post in January 27, 2010 about, Social Media in Kenyan Universities said, "University students are among the most avid users of social media in the country. They span the whole cycle because among them are content creators, passive readers, active participants, those who just share and a few who are yet to embrace social media." He suggests that while a few students buy Daily Papers, mobile internet ensures that all students get their information straight to their phones without hassles. And due to the sharing aspect of social media, the University Administration can rest assured that their communication will be shared to all corners of the university on the click of a button.

In addition, he observes that Social Media is a powerful listening tool and through it, Administrations can read the mood of the Universities especially when trouble is brewing. A perfect example is the recent disastrous Kenyatta University strike where those suspended were accused of using Facebook to plan the strike.

Moreso, to accommodate lecturers who are teaching in multiple Universities, social media as a way of ensuring that no lessons are missed by lecturers making presentations and upload them to platforms like Slideshare and/or Scribd [17] and students would then only need to download these on a weekly basis etc. and study them. Another way may be through the use of Podcasts or Video casts to complement the presentations if they are not self-explanatory or needed in-depth explanation. The lecturers would then just need to attend only one class a week to tackle any challenges or queries or go through the notes using a projector.

He adds that too many great events have been lost in memory because only TV stations have the only copies of them in their archives. Social Media allows anybody to use even phones to record such events and publish them online where those who missed or who are in need of a dose of inspiration can search and find them easily. Social Media is a platform that allows people to connect and better yet to reconnect. For Universities, this translates to connecting all its alumni through one platform and reaching all of them at the click of a button. The Alumni represent a great resource for any University and Universities can now get them together on one platform regardless of their geographical location. Facebook Groups, LinkedIn groups, and Twitter lists make for an ideal way of connecting the alumnus community of a given University.

\section{Theoretical Framework}

\section{Social learning/Social cognitive theory}

Albert Bandura (1970) established the most well-known theory of modern social learning, which proposes that people can learn in a social context. It states that behavior change is determined by environmental change, personal and behavioral elements. All of them affect each other. It focuses on the reciprocal interaction between these factors.

SCT emphasizes what people think and its effect on their behavior. This important concept states that there is a continuous, dynamic interaction between the individual, the environment, and behavior. Thus, a change in one of these factors impacts on the other two. SCT involves numerous key concepts, which have been associated with each of the three main constructs for the purpose of describing the SCT. Bandura conceptualized influences on behavior that involve the concept of person in terms of basic human capacities that are cognitive in nature.

Key concepts associated with the person include: personal characteristics, emotional arousal/coping, behavioral capacity, selfefficacy, expectation, expectancies, self-regulation, observational/ experiential learning, and reinforcement.

Main elements of this constructs that directly impact on how we integrate communication technologies in teaching and learning are: Behavioral capacity which refers to the individual's possession of both the knowledge and skills necessary to perform a behavior, Self- 
efficacy which refers to an individual's confidence in his or her ability to perform a behavior in various situations which is an important mediating variable between knowledge, attitudes, skills, and behavior; observational/experiential learning which refers to the acquisition of a behavior through observation and experience. Learning can occur either through observation of another's performance of a behavior (modeling), or through personal experience, i.e., trial and error and reinforcement which refers to the consequences that affect the probability a behavior will be tried again. Individuals are motivated to perform behaviors through rewards and incentives.

Research findings seem to indicate that informal contact and communication is the most prevalent form of transferring ICT knowledge [18]. Mcluhan Theory of Media ecology which is a theory on how media and communication process affect human perception and understanding suggest that media is an extension of our consciousness. Changes in technology change the symbolic environment, the socially constructed, sensory world of meanings that in turn shapes our perceptions, experiences, attitudes and behaviours. This proposition support Bandura's constructs on how environmental change affect personal and behavioral characteristics in learning and vice versa.

According to media systems dependency theory by Sandra BallRokeach and Melvin DeFleur, there is an internal link between media, audience and large social system. The audience learning from the real life is limited, so they can use media to get more information to fulfill their needs. An extensive use of media generates dependent relation in audience and also Media can able to create dependence relationship with target audiences to achieve their goals by using their media power.

Blumler and Elihu Katz [19], suggest that media users play an active role in choosing and using the media. Users take an active part in the communication process and are goal oriented in their media use. The approach suggests that people use the media to fulfill specific gratifications. The theorists say that a media user seeks out a media source that best fulfills the needs of the user. Uses and gratifications assume that the user has alternate choices to satisfy their need. Educationists will increasingly use the media that best meets the following needs: Cognitive needs, including acquiring information, knowledge and understanding; Affective needs, including emotion, pleasure, feelings; Personal integrative needs, including credibility, stability, status; Social integrative needs, including interacting with family and friends; and Tension release needs, including escape and diversion.

\section{Application}

Mayer E. Rchard of university of California Santa Barbara describes learning as the learner's construction of knowledge. The process by which people build mental representations from words, attitudes and pictures into knowledge. Learning can occur by observing others' behaviors and the resulting outcomes. Also learning can occur cognitively without a corresponding change in behavior. Finally modeled behavior is reinforced by producing desirable outcomes (for both the observed party and the learner).Three variables in the social learning context-the learner, the behavior, and the environment-can influence each other.

Ongoing improvements in personal technology and online communities have redefined what it means to be social and redefines what it means to teach and learn. The advantages of social learning, including learning by example and the reinforcement of knowledge that comes with the "human connection," are as valid today.
Social media sites such as Twitter, Facebook, LinkedIn, and Pinterest make it easy and motivate people to connect, share information, and develop relationships. Yet they can also provide the means to wander aimlessly, discovering people and information that may serve no value when it comes to learning.

When using these sites in the classroom, specific goals, directions, and guidelines on how to reach them (such as input from an instructor or lesson plan) can be used to facilitate formal social learning. However, social learning can also occur informally, without a pre-defined leader or curriculum, when topics originate organically from the learners themselves-for example, a group of students who get together to study for an upcoming test.

Modern day social learning is a reflection of the educational environment today's students have helped create for themselves (and future students) to perform at their best (Figure 2).

Mashable Tech [20] reported that after adopting a pilot social media learning program, the grades of one Portland, OR seventh grade class increased by more than $50 \%$ and $20 \%$ of student's school wide completed extra assignments for no credit.

\section{Emerging technologies for teaching and learning}

Emerging Technologies can be seen as tools for teaching and learning. A tool is any physical item that can be used to achieve a goal especially if it is not consumed in the process. New media tools such as web sites, search engines, blogs, podcasts, twitter, you tube, video conferencing are enhancing access and aiding research and innovations in education.

Hynes [21], texting or smsing is sending short messages between mobile phones, pdas and other hand held computers devices. It is instantaneous like a live conversation. It is discreet and in vibration mode, one can receive messages anywhere without disruption. It can also allow communication when one is traveling. Most people use it as a key way to send alerts and notification. However, the security of texting is questionable due to spamming.

Some short text messages are also difficult to decode. Some SMS formats are not compatible to some devices. Scholars question viability of this mode of communication in teaching and learning except perhaps in sending instructions and exchanging small bits of information but we cannot fail to appreciate its impact given the anxiety it arouses to invigilators during exam time.

Hynes [21], Pod casting is made up of downloadable audio and video that could be delivered to a portable media device. Podcasts are basically digital files that can be downloaded from the internet. The only common ingredients of a podcast are:-an audio-visual file,

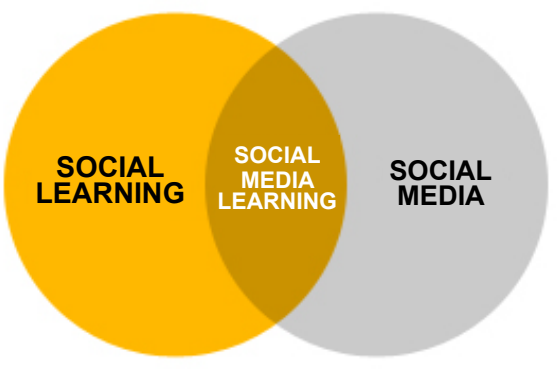

Figure 2: Social learning through social networking 
archival feature, accessibility to compute network, can be downloaded, transferable to a portable media player. Students can be able to access lots of materials uploaded by their lecturers through this method.

Hynes [21], A blog is shortened term for blogosphere or web blog. It can be for business or personal. Authoring a blog or maintaining a blog is called blogging. Individual articles are called blog posts or entries. It is a Personal online publishing system. People can write, publish and distribute opinions on any subject. They are also online diaries or special types of websites. Blogs as online journals typically display messages in reverse chronological order, i.e. Today's message will be shown above yesterdays. They are dynamic and need up-dating. It has evolved into an online conversation. Blogs are dynamic and user friendly, they encourage dialogue and can give immediate feedback. The disadvantage is that even the ignorant make their comment and can be a source of image crisis, incitement and time wastage if not monitored. Institutions should create a blogging policy for their workers and monitor constantly and remove comments that are offensive.

Hynes [21], live chat and video conferencing is a website live chart feature that show presenters speaking to each other online. Lecturers and other resource persons like counselors can use it to reach online audiences in far flung areas. It is cheap and does not require huge technology investment.

Hynes [21], E-mail is an electronic mail transmitted over the internet. You need to open an e-mail account to send and receive an e-mail. Most messages are sent via e-mail in the interest of time and dual notification. However, time- sensitive messages would better be delivered face-to-face or by phone. It is cheap and convenient to use. It is common for lecturers to send instructions via emails and get feedback through the same means.

Hynes [21], Phone calls are used when there are time sensitive issues especially in managing crisis in schools. Modern innovations have provided smart cellular phones with many features other than voice data. It is cheap but it may cause disruptions in a busy environment.

A Web site is a related collection of World Wide Web (WWW) files that includes a beginning file called a home page. A company or an individual tells you how to get to their Web site by giving you the address of their home page. From the home page, you can get to all the other pages on their site. A lot of information is provided on company web sites. They are dynamic thus up to date since the content is updated regularly. There is total control of content by the writer. The cost of maintaining and hosting a website is a bit high. There are free web hosting services, but with 'strings attached'. They will flood it with many adverts. It can be difficult for some people to navigate and retrieve information.

NMC Horizon Report [16], Virtual Worlds are richly immersive and highly scalable 3D environments, people enter these worlds via an avatar which is their representation in that space, moving their avatar through the space as if they were physically walking-or in some cases, flying. The most popular virtual worlds are multi-user spaces, meaning that many people can be in the same virtual space and interact with one another in real time. It is ideal for complex scientific experiments and recreation. This is an effective way of testing and demonstrating dangerous experimental concepts that cannot be done in real life. It is a technology that has led to many inventions today.

NMC Horizon Report [16], Visual Data Analysis blends highly advanced computational methods with sophisticated graphics engines to tap the extraordinary ability of humans to see patterns and structure in even the most complex visual presentations. Data Mashups is a web application that combines data from more than one source via a single, unified tool. Mashups are often about data visualization, but they can also be creative products of other kinds such as assorted film and music clips assembled into parodies of well-known productions.

Electronic Books [22] Support note-taking and research activities, and are beginning to augment these basic functions with new capabilities-from immersive experiences to support for social interaction-that are changing our perception of what it means to read. (Reference: American Libraries Association ebooks \& Digital Content.

NMC Horizon Report [12], Game-Based Learning research continues to demonstrate game-based learning effectiveness for students of all ages. Games for education span the range from single-player or small-group card and board games all the way to massively multiplayer online games and alternate reality games. (Source: 2011 NMC Horizon Report: Higher Ed Edition.) They provide an exciting 3D computers experience. These games are very addictive to their users because they provide a make believe environment that is thrilling almost like the real one. If well designed the multimedia video games can be used not only for recreation but also for education or training on some skills. Scientific illustrations using electronic models make maths exciting, real or less abstract. Science practicums are demonstrated in multimedia forms and can be replayed until the students understand.

NMC Horizon Report [16], Geolocation technology is available in a growing range of devices like mobile phones, cameras, and other handhelds; at the same time, the software tools we use every day are beginning to include features that make use of geolocative data instead of using manual maps and atlas. Using scanners texts are converted into digital forms. Maps from the survey of Kenya for instance are converted into electronic forms and other add ons and effects to make them more real are applied through formatting. Examples of maps in common usage include google maps. When making posters and adverts photographs are also scanned and glossy multi-media products are reproduced.

NMC Horizon Report [16], Semantic-aware applications are tools designed to use the meaning, or semantics, of information on the Internet to make connections and provide answers that would otherwise entail a great deal of time and effort.

An instructional simulation, also called an educational simulation, is a simulation of some type of reality (system or environment) but which also includes instructional elements that help a learner explore, navigate or obtain more information about that system or environment that cannot generally be acquired from mere experimentation. Instructional simulations are typically goal oriented and focus learners on specific facts, concepts, or applications of the system or environment. Students of medicine will understand human anatomy better if the human body model is used electronically and the surgical process undertaken virtually until the students gain the right competence before using human cadever.

User-produced video clips have increased, our notions of what constitutes useful or engaging video have been redefined-and more and more, it is a two to three minute piece designed for viewing in a three-inch browser window or on a mobile phone. That same phone is often the video capture device, with surprisingly high quality when viewed on a small screen.

Horizon Report [16], Learning Analytics refers to the interpretation of a wide range of data produced by and gathered on behalf of students 
in order to assess academic progress, predict future performance, and spot potential issues.

\section{Recommendations}

Institutions and especially at higher levels must increase uptake of this technologies or upgrade what they have as a matter of urgency. New technologies such as video conferencing, podcasting and simulators must assert their place in our classrooms. Here in Kenya the government laptop project should be implemented as a matter of urgency because it will produce a 'digital' generation that will transform all sectors of the economy radically. It is important to allocate more funds to ICT sector and related technologies.

\section{Conclusion}

Today the education environment is rich with a variety of learning technological aids which mainly complement the work of a classroom teacher in all levels of learning. When a classroom teacher or lecturer gives an assignment, the learner mostly uses a textbook or online resources such as search engines like google and Yahoo to track information from online book, journals, wikis, Encarta, dictionaries and thesaurus. Often the lecturer gives instructions through an e-mail or a sms and the learner submit the results through an e-mail.

Most modern computer labs especially in colleges and universities have capacity to simulate complex virtual experiments such as surgery and engineering which cannot be done in reality.

In Kenya, most government agencies have taken to social media and a lot of information is provided online. Education institutions such as Kenya National Examination council is registering candidates and releasing exams online. The university Joint Admission Board requires students to apply online. Also most schools and college alumni remain connected long after school through social network.

Teachers conveniently use PowerPoint with overhead projectors and other audio-visual aids to enhance delivery especially in literature set books.

Computer software such as graphic designer and sage have made difficult tasks in design and accounting easier hence making work and learning fun. These tools nurture talents and open doors for new careers. Indeed a school leaver who cannot apply for a job online will be greatly disadvantaged in this decade.

Melita of Teachers Service Commission [23,24] says fears, anxiety, and concern that teachers have about change must be addressed. Using technology as a teaching and learning tool in the classroom does bring fear, anxiety and concern to a greater extent since it involves both changes in classroom procedures and the use of the often-unfamiliar technologies [25]. Content development is a critical area that is too often overlooked. The lack of culturally appropriate educational content, particularly for developing countries, poses challenges. Cultural differences affect learners' ability to fully understand and benefit from the lessons and their intended learning outcomes. It is, therefore, clear that content produced in one context cannot be adopted without some modification into another context. The bulk of existing ICT-based educational material is likely to be in English, and thus of little relevance to education in developing countries (especially at the primary and secondary levels) [26].

In summary researchers acknowledge that technology is enhancing education and access to it through e-learning by:

- Providing teachers with digital materials to supplement traditional lectures (via laptops and projectors);

- Delivering master teacher sessions by video to wide audiences, computer-based games and simulations;

- Replacing books with electronic devices supporting more engaging and comprehensive content;

- Enabling collaboration across communities via connected classrooms;

- Supplementing traditional curricula with additional learning materials covering locally-relevant topics like health and agriculture;

- Delivering teacher training in local schools during evenings and weekends;

- Delivering vocational training and adult education via school infrastructure during non-school hours;

- Offering individual, self-paced training tailored to individual needs and goals; and

- Extending education beyond the classroom via mobile devices, personal computers or Internet kiosks.

\section{Acknowledgement}

JKUAT University School of Social Sciences and Human Resource development, Department of Mass communication; my instructor Dr. E. Miring'u and supervisor Dr. H. Mberia.

\section{References}

1. Cuba: In the Shadow of Doubt (1986) IMBD

2. Norman DA (1993) Things That Make Us Smart. Reading, MA: AddisonWesley Publishing Company.

3. Eric M (2008) Theory of communication: the year Global Media journal.

4. Shannon Rupp (2012) Technology, e-learning and education in Africa. CAI.

5. Berliner DC, Calfee RC (1996) Cognition and technology group at Vanderbilt.

6. Mayer RE, Introduction to Multimedia learning. University of California, Santa Barbara.

7. World Telecommunication/ICT Indicators database (2014) International Telecommunication Union.

8. Moving forward in Rwanda's Education: Interview with Dr. Charles Murigande, Minister of Education (2014) Republic of Rwanda.

9. The World in 2014: ICT Facts and Figures (2014) International Telecommunication Union (ITU).

10. Internet Users (2014) Internet Live Stats.

11. Core ICT Indicators (2010) International Telecommunication Union (ITU).

12. Internet users reaches $19.6 \mathrm{~m}$ in Kenya (2013) humanipo.

13. Lawson Shawn, New Media and Education

14. Cambridge Online Dictionary (2014).

15. Manovich L (2001) The Language Of New Media. Cambridge: MIT Press. 16. NMC Horizon Report (2007).

17. CCK Sector Statistics for Quarter 2 - 2012-2013 (2013) Scribd

18. Pelgrum, Law (2003) ICT in education around the world: trends, problems and prospects. UNESCO: International Institute for Educational Planning.

19. Blumler, Katz E (1974) The Uses of Mass Communications: Current Perspectives on Gratifications Research. Sage 40: 132-133.

20. Mashable Tech. 
Citation: Ngugi PK (2014) Harnessing Emerging Technologies for Education Communication. J Mass Communicat Journalism 4: 207. doi:10.4172/21657912.1000207

Page 8 of 8

21. Geraldine HE (2010) Managerial Communication: Strategies and Applications. 5th Ed. McGraw Hill.

22. eBooks and Digital Content, American Libraries Association.

23. David Melita Katitia;Teachers Service Commission.
24. Melita K (2005) The role of ICT integration into classroom in kenya. A literature review. Academia.edu.

25. Bitner N, Bitner J (2002) Integrating Technology into the Classroom: Eight Keys to Success. Journal of Technology and Teacher Education.

26. Tinio (2003) ICT in Education. UNDP. 